\title{
A GESTÃO DO PODER JUDICIÁRIO SOB A ÓTICA DE EX-CONSELHEIROS: Análise da Relação entre o CNJ e a Justiça Estadual de 2004 a 2013
}

\author{
Leonel Gois Lima Oliveira'
}

\section{Palavras-Chave}

poder judiciário / justiça estadual /

Conselho Nacional de Justiça

\section{Introdução}

\section{A Gestão do Poder Judiciário com o}

\section{Conselho Nacional de Justiça}

3. Procedimentos Metodológicos

4. O olhar desproporcional do CNJ

5. A Relação entre o CNJ e os Tribunais de Justiça estaduais

Considerações Finais

Referências

\section{Resumo}

O objetivo de pesquisa consiste em analisar a interação do CNJ com os tribunais estaduais em busca de melhorar os níveis de eficiência da Justiça Estadual no período de 2004 a 2013 na ótica dos ex-conselheiros. Os principais questionamentos a serem respondidos foram: De que forma os esforços e ações realizados pelos Tribunais de Justiça estaduais se adequaram as exigências do CNJ visando à melhoria da eficiência da prestação jurisdicional? Em que medida tem ocorrido uma convergência de esforços e alcance de resultados entre o $\mathrm{CNJ}$ e os Tribunais de Justiça para a melhoria da eficiência? Foram entrevistados 20 ex-conselheiros, adotando-se a análise temática ou categorial como forma principal de técnica de análise de conteúdo. As categorias estabelecidas para análises foram relacionadas ao predomínio de divergência (desconfiança e resistências), ao predomínio de convergência (aceitação e integração) e à alternância de cenários (relativismo e contexto de autonomia). De forma geral, os respondentes apontaram a existência de uma convergência de esforços entre o $\mathrm{CNJ}$ e os Tribunais de Justiça estaduais que foi sendo fortalecida na medida em que o desconhecimento e a desconfiança sobre o CNJ foram se dissipando. Percebeu-se que a relação de convergência e divergência apresenta alternâncias, pois o entendimento varia conforme a percepção de perda de autonomia por parte dos tribunais. 


\title{
THE JUDICIAL BRANCH MANAGEMENT FROM THE PERSPECTIVE OF EX- COUNCILORS: Analysis of the Relationship between the CNJ and the State Court from 2004 to 2013
}

\author{
Leonel Gois Lima Oliveira
}

\section{Keywords}

judiciary branch / state court /

National Court of Justice

\section{Abstract}

The research objective is to analyze the interaction of the $\mathrm{CNJ}$ with the state courts in order to improve the efficiency levels of the State Justice from 2004 to 2013 from the perspective of ex-councilors. The main questions to be answered were: How have the efforts and actions taken by the State Courts fit the CNJ's requirements aimed at improving the efficiency of the jurisdictional provision? To what extent has there been a convergence of efforts and results achieved between the $\mathrm{CNJ}$ and the State Courts to improve efficiency? Twenty ex-councilors were interviewed, adopting thematic or categorical analysis as the main form of content analysis technique. The categories established for analysis were related to the predominance of divergence (distrust and resistance), the predominance of convergence (acceptance and integration) and the alternation of scenarios (relativism and context of autonomy). In general, respondents pointed to the existence of a convergence of efforts between the CNJ and the State Courts that was being strengthened as the ignorance and distrust about the CNJ gradually dissipated. It was noticed that the relationship of convergence and divergence presents alternations, because the understanding varies according to the perception of loss of autonomy by the courts. 


\section{INTRODUÇÃO}

É recorrente uma visão do Poder Judiciário que se encontra relacionada com a lentidão e demora excessiva na resolução dos conflitos, a percepção de elevados custos, o sentimento de impunidade e a ausência de transparência de suas atividades. Por outro lado, ocorreram mudanças na maneira de gerir os tribunais que permitiram visualizar melhorias no nível de satisfação do brasileiro em relação ao Judiciário a partir da segunda metade da década de 2000. 0 monitoramento do desempenho dos tribunais, ocasionados por maior transparência, demonstra melhorias na gestão judiciária, embora ainda se verifique pontos a serem aperfeiçoados, possibilitando alterar algumas opiniões enraizadas no senso comum do brasileiro sobre o Poder Judiciário (Falcão, 2009). O principal marco consiste na Emenda Constitucional (EC) 45/2004, mais conhecida por "Reforma do Judiciário", que buscou fornecer uma resposta para a meIhoria do desempenho ao criar uma instituição de controle administrativo, o Conselho Nacional de Justiça (CNJ). O objetivo do CNJ consiste em realizar um controle administrativo e financeiro de todos os tribunais brasileiros, inclusive os tribunais superiores (Oliveira, 2017).

Observam-se poucos estudos sobre a Gestão do Poder Judiciário na área de conhecimento da Administração Pública, mesmo com a maior disponibilidade de dados, diagnósticos, mecanismos de transparência e acompanhamento dos tribunais desenvolvido e divulgados pelo CNJ (Nogueira, 2011; Oliveira, Nogueira, \& Pimentel, 2018). Portanto, os levantamentos demonstraram uma lacuna sobre o papel do CNJ na melhoria do desempenho do segmento da Justiça Estadual. O objetivo de pesquisa consiste em analisar a interação do CNJ com os tribunais estaduais em busca de melhorar os níveis de eficiência da Justiça Estadual no período de 2004 a 2013 na ótica dos ex-conselheiros. Os principais questionamentos a serem respondidos foram: De que forma os esforços e ações realizados pelos Tribunais de Justiça estaduais se adequaram as exigências do CNJ visando à melhoria da eficiência da prestação jurisdicional? Em que medida tem ocorrido uma convergência de esforços e alcance de resultados entre o $\mathrm{CNJ}$ e os Tribunais de Justiça para a melhoria da eficiência?

O estudo apresenta um enfoque sobre a Gestão do Poder Judiciário por meio da atuação do CNJ e logo após são detalhados os procedimentos metodológicos adotados. Em seguida, tem-se as análises sobre a desproporcionalidade do CNJ e a relação do referido órgão com os Tribunais de Justiça.

\section{A GESTÃO DO PODER JUDICIÁRIO COM O CONSELHO NACIONAL DE JUSTIÇA}

A Gestão do Poder Judiciário no Brasil se confunde com a história do $\mathrm{CNJ}$, podendo ser contada alguns anos antes de sua criação. A tentativa por estabelecer um controle do Judiciário já foi buscada anteriormente na história do país. Portanto, o CNJ não foi a primeira instituição com um formato de Conselho de Justiça no sistema jurídico-constitucional brasileiro. O ineditismo aconteceu com a criação do Conselho Superior da Magistratura durante o regime militar por meio da Emenda Constitucional 7/1977. Os integrantes do Supremo Tribunal Federal (STF) atuavam em sua composição e disciplinavam os comportamentos considerados inadequados dos magistrados. Não houve grandes interferências pelo ConseIho, pois o período de abertura política veio 
logo em seguida, sendo o referido órgão destituído com a Constituição Federal (CF) de 1988 (Sadek, 2004; 2006; Sampaio, 2007; Peleja Júnior, 2011).

Em 1992, houve uma retomada da ideia de controle do Judiciário, pois uma maior transparência e fiscalização da magistratura brasileira era solicitada por um grupo organizado de representantes do Poder Legislativo. Ocorreram muitos debates sobre a forma de atuação deste novo Conselho, envolvendo uma Comissão Parlamentar de Inquérito para intensificar todo este processo e ainda contou com a mudança de relatoria do projeto por três vezes. Por outro lado, a principal mensagem deste período histórico consiste num esforço político para a criação de uma instituição de controle externo do Poder Judiciário ou para o estabelecimento de mais uma instância de julgamento colegiada com a participação de representantes de outras instituições (membros do Ministério Público, da Ordem dos Advogados e membros do Poder Legislativo). Os magistrados fizeram grandes manifestações de resistências, ocasionando na rejeição dessa proposta. Inclusive, era bastante mencionada a possibilidade de ser declarada inconstitucional pelo próprio STF (Sampaio, 2007; Sadek \& Arantes, 2010; Peleja Júnior 2011).

O CNJ foi introduzido no artigo 103-B da CF como um órgão judicial de controle interno e assessoramento e não como mais uma organização que representasse uma nova instância de julgamentos. Portanto, encontra-se numa posição hierarquicamente inferior ao STF, mas superior em relação aos tribunais superiores (Vieira; Pinheiro, 2008; Nogueira, 2010; Oliveira, 2017). Neste caso, o CNJ promove políticas judiciárias por meio de resoluções e recomendações a serem seguidas pelos tribunais em todos os seg- mentos do Judiciário. Mesmo assim, há um entendimento de que a referida Reforma do Judiciário impactou, principalmente, o STF ao beneficiá-lo com os institutos da Repercussão Geral e da Súmula Vinculante, fazendo com que diminuísse a demanda por seus serviços e dando agilidade a um maior número de julgamentos (Falcão, Cerdeira, \& Arguelhes, 2011; Falcão, Abramovay, Leal, \& Hartmann, 2013).

O CNJ é composto por quinze membros com mandato de dois anos, sendo admitida uma recondução. Os quinze membros são: i) O presidente do STF; ii) um Ministro do Superior Tribunal de Justiça (STJ), indicado pelo respectivo tribunal; iii) um Ministro do Tribunal Superior do Trabalho (TST), indicado pelo respectivo tribunal; iv) um desembargador de Tribunal de Justiça (TJ), indicado pelo STF; v) um juiz estadual indicado pelo STF; vi) um juiz de Tribunal Regional Federal (TRF), indicado pelo STJ; vii) um juiz federal, indicado pelo STJ; viii) um juiz do Tribunal Regional do Trabalho (TRT), indicado pelo TST; ix) um juiz do trabalho, indicado pelo TST; $x$ ) um membro do Ministério Público da União (MPU), indicado pela Procuradoria-Geral da República (PGR); xi) um membro do Ministério Público estadual, escolhido pela PGR dentre os nomes indicados pelo órgão competente de cada instituição estadual; xii) dois advogados, indicados pelo Conselho Federal da Ordem dos Advogados do Brasil (OAB); xiii) dois cidadãos, de notável saber jurídico e reputação ilibada, indicados um pela Câmara dos Deputados e outro pelo Senado Federal. Deste modo, evidencia-se uma predominância de magistrados, reforçando a função de atuar como um órgão de controle interno do Poder Judiciário (Nogueira, 2010).

O CNJ exerce não apenas o controle admi- 
nistrativo, mas também atua com um enfoque fiscalizatório e punitivo sobre desvios de conduta e irregularidades promovidas por magistrados ou pelos tribunais. Ao atuar no controle dos tribunais, os agentes políticos podem utilizar o Conselho como mais um instrumento tático no ambiente institucional judicial. Fragale Filho (2011; 2013), por exemplo, demonstra como as dimensões de construção da agenda, dos membros da composição e das possibilidades de construção do processo decisório no CNJ ainda sofrem influências externas devido ao baixo nível de institucionalização do órgão.

Os padrões políticos também são evidenciados dentro do órgão de controle do Judiciário, afetando o formato de atuação da instituição. Nesse sentido, Fragale Filho (2011; 2013) reforça a importância de entender melhor a composição do CNJ para apontar padrões de atuação na pauta do referido órgão. Percebem-se alterações nos desenhos institucionais das composições iniciais do CNJ gerando preocupações sobre as mudanças de rumos que podem ocorrer com maior envolvimento político dos indicados. Neste entendimento, Falcão e Rangel (2013) indicam elementos que poderiam nortear os procedimentos de indicações de magistrados e de cidadãos para o cargo de conselheiro do CNJ. Sugere-se regulamentar os processos seletivos para a escolha do indicado, considerando os seguintes aspectos: a capacidade de gestão, ou competência; e a independência moral, ou isenção no exercício do controle administrativo e financeiro. Prever ainda o combate às indicações que apontem para casos de nepotismo e de candidatos condenados por ato de improbidade administrativa (Falcão, \& Rangel, 2013).

Desde o ano de 2009, foram iniciados os esforços de nivelamento com o estabeleci- mento de metas nacionais que eram ligadas a pelo menos um dos objetivos estratégicos. A essência da ideia consistia em atribuir metas que deveriam ser cumpridas no próprio ano em que elas foram estabelecidas. As metas eram propostas pelo $\mathrm{CNJ}$, votadas e referendadas pelos presidentes de todos os tribunais do país durante os Encontros Anuais do Judiciário. Tratava-se de um encontro realizado sempre no ano anterior, facilitando a divulgação e o conhecimento das metas deste o início do ano para adequação dos esforços para o alcance das metas. Os procedimentos reforçavam os aspectos de centralização e uniformização do Judiciário (Glick, 1983), além de operacionalizar o conceito do Balanced Scorecard (BSC) com as medições do alcance das metas (Kaplan; Norton, 2004). A adoção do BSC nos tribunais contou com a participação de uma consultoria, sendo estabelecida como a Meta 1 do ano de 2009 (Gangemi \& Fernandes, 2010).

As lições aprendidas com a utilização das metas nos primeiros anos (2009 e 2010) foram essenciais para alterar o rumo nos anos posteriores. O descumprimento da maior parte das metas pelos tribunais foi motivo para críticas recorrentes da imprensa. Algumas metas foram muito desafiadoras, expondo a fragilidade do Judiciário para a sua implementação por completo. O CNJ acabou promovendo um grave problema de medição de produtividade e ocasionou uma elevação da mensuração de informações nos tribunais que não estavam devidamente preparados, além de ter indicadores focados no curto prazo (Bouckaert \& Balk, 1991; Fragale Filho, 2007).

\subsection{O Judiciário num enfoque administra- tivo e o contexto da eficiência}


Algumas mudanças foram propostas pelo próprio $\mathrm{CNJ}$ para retomar adequadamente o foco estratégico, a saber: definição de metas por segmentos do Judiciário (por exemplo, a Justiça Estadual poderia ter metas diferentes da Justiça Eleitoral); redução da quantidade de metas (não havia mais a obrigatoriedade de ter dez metas por ano); antecipação da divulgação de metas para os anos seguintes (divulgava as metas de dois anos seguintes), facilitando a garantia de busca de recursos orçamentários que seriam vinculados diretamente a projetos de cumprimento das metas; foco nas metas não cumpridas em anos anteriores e reconhecimento pelo cumprimento (visava garantir a continuidade dos esforços e reconhecia os méritos das unidades judiciais que conseguiam o cumprimento). As mudanças foram fundamentais para aumentar o nível de cumprimento e deixou claro que o CNJ atuava administrativamente nos seguintes temas: gestão; controle; organização; padronização de procedimentos processuais e de rotinas judiciárias; magistratura e política social. O CNJ, também, tem abordado questões polêmicas para o serviço público como, por exemplo, o combate ao nepotismo; as regras para o pagamento de precatórios; a restrição da quantidade de servidores cedidos de outros poderes e alteração das regras de promoção dos magistrados na carreira (Oliveira, 2017).

Ao lidar com assuntos relativos à sua gestão, o Poder Judiciário brasileiro sempre careceu de mecanismos que permitissem um conhecimento mínimo de sua organização administrativa. Freitas (1987) aponta que foi o pioneiro no Judiciário brasileiro a trabalhar com a ideia de uma Justiça Eficiente. Acabou sendo incompreendido na época e esta percepção ficou presente até meados da década de 2000. Era difícil conseguir responder de forma mais precisa alguns questionamentos que envolvessem a quantidade de magistrados ou de servidores, a quantidade de casos (processos) novos, a quantidade de casos finalizados, o orçamento dos tribunais, dentre outros dados básicos à administração de uma organização de tal porte (Sadek, 2004; Azevedo, 2010; Nogueira, Oliveira, Vasconcelos \& Oliveira, 2012). Na tentativa de tratar esse problema, o movimento de coleta de dados gerenciais começou por diferentes frentes, desde dados mais agregados até dados mais individualizados, bem como a identificação dos maiores demandados da prestação jurisdicional (chamados tecnicamente de litigantes).

Desde 2006, o CNJ passou a recolher e sistematizar dados estatísticos referentes a aspectos ligados ao desempenho das organizações judiciárias brasileiras. Os dados, após tratamentos estatísticos, eram apresentados em forma de indicadores agrupados em áreas como: insumos, dotações orçamentárias, litigiosidade e acesso à justiça (DPJ, 2014; 2018). Estes dados são divulgados por intermédio de relatório anual intitulado Justiça em Números. Os dados apresentados são considerados agregados, pois retrata a situação consolidada dos tribunais. Há subdivisões por competência e jurisdição ainda em nível macro $\left(2^{\circ} \mathrm{Grau} ; 7^{\circ} \mathrm{Grau}\right.$; Turmas Recursais; e Juizados Especiais), mesmo assim os dados não refletem a situação das competências da justiça ou das unidades judiciárias de forma isoladas (DPJ, 2014; 2018; Nogueira et al., 2012).

Macieira e Maranhão (2010) destacam a importância de trabalhar com noções de gestão nas unidades judiciárias, servindo como instrumentos para a adoção de boas práti- 
cas desde a base do Poder Judiciário. Deste modo, pensando na formação de um banco de dados que contemplasse questões mais relativas a um nível micro, o CNJ desenvolveu o programa Justiça Aberta no final de 2007. Trata-se de um programa gerenciado pela Corregedoria Nacional de Justiça que permite fornecer elementos maiores de transparência, bem como informações que permitam facilitar o acesso à justiça. $O$ sistema Justiça Aberta apresenta dados tanto das serventias judiciais ( $1^{\circ}$ e $2^{\circ}$ grau), como das extrajudiciais (cartórios), mas apenas refere-se à competência da Justiça Estadual. Castro (2011) ressalta a importância desta base por fornecer dados desagregados em relação ao relatório Justiça em Números, permitindo servir como um melhor instrumento para análise e formulação de políticas judiciárias considerando as peculiaridades das unidades judiciárias. Dado a heterogeneidade do Judiciário brasileiro, este programa permite analisar de forma mais detalhada a evolução mensal das deficiências e virtudes de cerca de nove mil unidades jurisdicionais espalhadas por todo o país. O nível de detalhamento permite fornecer informações como, por exemplo: o número de funcionários, o estoque de processos pendentes, a quantidade de suspensão de liminares (pedidos de suspensão), o volume de despachos e decisões interlocutórias, a quantidade de processos distribuídos e resolvidos (sentenças e acordos homologados).

\section{PROCEDIMENTOS METODOLÓGICOS}

As diferentes composições de conselheiros servem como referência para uma maior ou menor influência do CNJ no ambiente institucional que se encontra o segmento da Justiça Estadual. Os anos de 2004 a 2013 foram escolhidos por corresponder ao período em que o CNJ vem anualmente coletando dados sobre os tribunais brasileiros e publicando-os nos relatórios Justiça em Números (DPJ, 2014; 2018). Além disso, representa uma década desde a criação do $\mathrm{CNJ}$ e dos efeitos gerados pela Reforma do Judiciário.

Inicialmente, foram realizadas entrevistas de caráter exploratório com dois ex-conselheiros do CNJ. A escolha dos entrevistados foi por critério de acessibilidade e conveniência e cada um atuou no CNJ em gestões distintas. Além disso, os entrevistados tinham um maior relacionamento com outros ex-conseIheiros e demonstraram fundamentais para facilitar o acesso dos entrevistados na fase principal da pesquisa. Desta forma, pôde-se compreender melhor o processo de formação do conselho e os distintos mecanismos utilizados para a melhoria das eficiências dos tribunais. Estas visões também possibilitaram comentários sobre casos pontuais que agregam o contexto local dos tribunais estaduais e auxiliaram na construção e aprimoramento da versão final do roteiro de entrevistas. Foi recomendado que as entrevistas não fossem gravadas, pois haveria a possibilidade de obter mais informações, evitando possível intimidação por parte dos ex-conselheiros. Nesse sentido, verifica-se a observação de Beaud e Weber (2007) que a posição ou status do entrevistado pode gerar dificuldades para a gravação. Por outro lado, é necessário ficar mais atento ao que for dito pelos entrevistados, tomando notas e registrando os detalhes da entrevista logo após a sua finalização.

A amostra foi construída por ex-conselheiros do CNJ, fornecendo uma perspectiva longitudinal. Os seguintes critérios foram adotados para a seleção da amostra: i) Conselheiro(a) Presidente; ii) Conselheiro(a) Corregedor(a); iii) Conselheiro(a)s representan- 
tes da Justiça Estadual; iv) Conselheiro(a)s representantes do Ministério Público Estadual; v) Conselheiro(a)s indicados pela OAB; vi) Conselheiro(a)s indicados pelo Poder Legislativo (cidadãos representantes da Câmara Federal e do Senado); vii) Conselheiro(a)s representantes de outros segmentos do Judiciário, mas que tiveram participação direta em comissões ou projetos voltados para a melhoria da eficiência operacional dos tribunais. O estabelecimento destes critérios serviu para selecionar as amostras de acordo com as composições do CNJ. O resumo dos contatados e da quantidade de entrevistados por composição pode ser visto da Tabela 1.

Tabela 1: Resumo da amostra de entrevistados por composição.

\begin{tabular}{|c|c|c|c|c|c|}
\hline Composição & Total & Contatados & Entrevistados* & Total & Contatados \\
\hline $1^{a}$ & 15 & 8 & 6 & $53,3 \%$ & $75,00 \%$ \\
\hline $2^{a}$ & 17 & 10 & 6 & $58,8 \%$ & $60,00 \%$ \\
\hline $3^{a}$ & 15 & 6 & 5 & $40,0 \%$ & $83,33 \%$ \\
\hline $4^{a}$ & 15 & 6 & 4 & $40,0 \%$ & $66,67 \%$ \\
\hline $5^{a}$ & 15 & 8 & 2 & $53,3 \%$ & $25,00 \%$ \\
\hline
\end{tabular}

Fonte: Elaborado pelo autor.

*Houve entrevistados que foram reconduzidos e participaram de mais de uma composição.

Observa-se que obteve percentual acima de $60 \%$ de ex-conselheiros contatados em todas as composições (três entrevistados foram reconduzidos ao cargo e, portanto, foram contabilizados em cada uma das composições). Apenas os conselheiros da $5^{a}$ composição que se mantiveram mais difíceis para a realização das entrevistas e ob- teve-se o percentual de $25 \%$. Consideram-se válidos os quantitativos de entrevistas por composição, pois permite obter uma quantidade razoável de informações e opiniões ao fornecer uma perspectiva longitudinal da estruturação e atuação do CNJ.

As entrevistas obedeceram a protocolos 
de pesquisa para preservar a identidade dos respondentes, fornecendo segurança e liberdade de expressar as suas opiniões, apresentando casos ou situações que envolveram os bastidores das reuniões e sessões do CNJ. Os protocolos foram os seguintes: i) encaminhamento prévio do roteiro de entrevista; ii) as entrevistas foram realizadas isolada e privadamente; iii) não realização de gravações; iv) tomada de notas e observações durante a entrevista; v) fornecimento de papel para os entrevistados produzirem rascunhos ou anotações enquanto eram entrevistados; vi) os participantes não conheceram as respostas um dos outros; vii) as questões formuladas foram circunscritas ao domínio que se queria investigar; viii) solicitou assinatura do protocolo de realização de pesquisa e deixou uma cópia do roteiro com o entrevistado (Thiry-Cherques, 2008).

A Figura 1 apresenta o resumo das informações sobre as entrevistas realizadas de junho a outubro de 2014: i) Código de identificação do (a) entrevistado (a); ii) Data de realização da entrevista; iii) Local de realização da entrevista; iv) Duração em minutos da entrevista; v) Período em que o (a) entrevistado (a) esteve no CNJ; vi) Indicação da composição do CNJ; vii) Ocupações atuais do (a) entrevistado (a), sendo uma principal e outra subsidiária caso tenha outra ocupação. O código de identificação pode ser compreendido a partir desta legenda:

- $\quad$ LEG = Cidadão (ã) indicado (a) pelo Legislativo;

- $\quad M A G=$ Magistrado (a) indicado pelo STF, STJ ou TST;

- $\quad$ MPE = Promotor (a) de Justiça indicado (a) pela PGR;

- $\mathrm{OAB}=$ Advogado (a) indicado (a) pela $\mathrm{OAB}$.
Os entrevistados foram informados que a entrevista teria uma duração média de 45 minutos, pois foi o tempo médio observado durante as entrevistas exploratórias e entrevistas estruturadas da etapa anterior. As entrevistas totalizaram quase 19 horas de duração, tendo uma média de aproximadamente 57 minutos por encontro. Apresentou uma amplitude de aproximadamente 1 hora (62 minutos). As entrevistas de maior duração foram realizadas com os entrevistados que possuíam maior experiência e vivência com a gestão dos tribunais enquanto atuou no CNJ. As mais curtas foram consequências de dois fatores: i) a falta de familiaridade com o tema de gestão, e ii) devido à restrição de tempo que o (a) entrevistado (a) possuía na sua agenda. O local da entrevista foi indicado para demonstrar que as entrevistas mais longas foram realizadas num ambiente mais tranquilo e com uma quantidade menor de interrupções. Conforme Beaud e Weber (2007), um local favorável para o entrevistado possibilitou um clima de maior confiança, fornecendo um maior detalhamento nas respostas que foram fundamentais para os esclarecimentos do contexto de cada composição.

Após as entrevistas, as anotações eram repassadas para relatórios de entrevistas que serviam para pontuar os principais pontos e identificar relações com o referencial teórico. Era o momento de comparar as informações obtidas com as categorias previamente estabelecidas e retiradas da literatura estudada. Os entrevistados mencionavam livros, artigos e documentos que eram eventualmente agregados ao material já colhido na fase de pesquisa documental e bibliográfica. 


\begin{tabular}{|c|c|c|c|c|c|c|}
\hline Código & Local & Duração (min) & $\begin{array}{l}\text { Período no } \\
\text { CNJ }\end{array}$ & Composição & \multicolumn{2}{|c|}{ Ocupações atuais } \\
\hline LEG01 & $\begin{array}{l}\text { Escritório de } \\
\text { Advocacia }\end{array}$ & 73 & $2005-2007$ & $1^{\mathrm{a}}$ & Advogado (a) & - \\
\hline LEG02 & Hotel & 44 & $2005-2009$ & $1^{a}$ e $2^{a}$ & Professor (a) & - \\
\hline MAG01 & $\begin{array}{l}\text { Gabinete do } \\
\text { Magistrado (a) }\end{array}$ & 42 & 2005-2007 & $1^{\mathrm{a}}$ & Magistrado (a) & - \\
\hline MAG02 & $\begin{array}{l}\text { Gabinete do } \\
\text { Magistrado (a) }\end{array}$ & 32 & $2011-2012$ & $4^{a}$ & Magistrado (a) & Desembargador (a) \\
\hline MPEOI & $\begin{array}{l}\text { Entidade de } \\
\text { Classe }\end{array}$ & 40 & 2007-2011 & $2^{\mathrm{a}} e 3^{\mathrm{a}}$ & $\begin{array}{l}\text { Promotor (a) de } \\
\text { Justiça }\end{array}$ & - \\
\hline MAG03 & $\begin{array}{l}\text { Residência do } \\
\text { Magistrado }\end{array}$ & 75 & 2007-2009 & $2^{a}$ & $\begin{array}{l}\text { Magistrado (a) } \\
\text { Aposentado (a) }\end{array}$ & $\begin{array}{l}\text { Desembargador (a) } \\
\text { Aposentado (a) }\end{array}$ \\
\hline MAG04 & $\begin{array}{l}\text { Gabinete do } \\
\text { Magistrado (a) }\end{array}$ & 55 & 2008-2009 & $3^{a}$ & Magistrado (a) & $\begin{array}{l}\text { Ministro(a) Tribunal } \\
\text { Superior }\end{array}$ \\
\hline OABO1 & $\begin{array}{l}\text { Escritório de } \\
\text { Advocacia }\end{array}$ & 67 & 2009-2012 & $3^{a} e 4^{a}$ & Advogado (a) & - \\
\hline OABO2 & $\begin{array}{l}\text { Entidade de } \\
\text { Classe }\end{array}$ & 56 & $2007-2009$ & $2^{a}$ & Advogado (a) & $\begin{array}{l}\text { Representante de } \\
\text { Classe }\end{array}$ \\
\hline MAG05 & $\begin{array}{l}\text { Gabinete do } \\
\text { Magistrado (a) }\end{array}$ & 71 & 2007-2009 & $2^{a}$ & Magistrado (a) & - \\
\hline MAG06 & $\begin{array}{l}\text { Escritório de } \\
\text { Advocacia }\end{array}$ & 48 & $2005-2007$ & $1^{\mathrm{a}}$ & Advogado (a) & $\begin{array}{l}\text { Magistrado (a) Apo- } \\
\text { sentado (a) }\end{array}$ \\
\hline OABO3 & $\begin{array}{l}\text { Escritório de } \\
\text { Advocacia }\end{array}$ & 52 & $2005-2007$ & $7^{a}$ & Advogado (a) & - \\
\hline MAG07 & $\begin{array}{l}\text { Residência do } \\
\text { Magistrado }\end{array}$ & 65 & $2005-2006$ & $1^{\mathrm{a}}$ & Advogado (a) & $\begin{array}{l}\text { Magistrado (a) Apo- } \\
\text { sentado (a) }\end{array}$ \\
\hline MAG08 & $\begin{array}{l}\text { Gabinete do } \\
\text { Magistrado (a) }\end{array}$ & 78 & $2011-2012$ & $4^{a}$ & Magistrado (a) & - \\
\hline LEG03 & Universidade & 43 & 2009-2011 & $3^{a}$ & Professor (a) & - \\
\hline MAG09 & $\begin{array}{l}\text { Gabinete do } \\
\text { Magistrado (a) }\end{array}$ & 28 & 2009-2011 & $3^{a}$ & Magistrado (a) & $\begin{array}{l}\text { Ministro (a) Tribunal } \\
\text { Superior }\end{array}$ \\
\hline MAG1O & $\begin{array}{l}\text { Gabinete do } \\
\text { Magistrado (a) }\end{array}$ & 85 & $2013-2014$ & $5^{a}$ & Magistrado (a) & Conselheiro (a) CNJ \\
\hline MAG11 & $\begin{array}{l}\text { Gabinete do } \\
\text { Magistrado (a) }\end{array}$ & 39 & $2008-2009$ & $2^{a}$ & Magistrado (a) & $\begin{array}{l}\text { Ministro (a) Tribunal } \\
\text { Superior }\end{array}$ \\
\hline MAG12 & $\begin{array}{l}\text { Gabinete do } \\
\text { Magistrado (a) }\end{array}$ & 55 & $2013-2014$ & $5^{a}$ & Magistrado (a) & Conselheiro (a) CNJ \\
\hline MAG13 & Hotel & 90 & $2011-2012$ & $4^{a}$ & $\begin{array}{l}\text { Magistrado (a) } \\
\text { Aposentado (a) }\end{array}$ & $\begin{array}{l}\text { Ministro (a) Tribunal } \\
\text { Superior }\end{array}$ \\
\hline
\end{tabular}

Figura 1: Informações sobre os entrevistados e entrevistas realizadas.

Fonte: Elaborado pelo autor.

Buscou-se entrevistar a maior quantidade possível de ex-conselheiros, embora a saturação no nível de respostas já era percebida a partir da $14^{a}$ entrevista realizada. Continuou-se com as outras entrevistas por causa da relevância dos respondentes no processo de estruturação do CNJ. A saturação apare- ce quando o acréscimo de informações e dados em uma pesquisa não altera a compreensão do fenômeno estudado (Creswell, 2009; Thiry-Cherques, 2008; 2009). Portanto, o número de entrevistas realizadas ficou vinculada a critérios ex-post. A quantidade foi em função das respostas obtidas e não 
arbitradas de forma pré-determinada, pois não é possível definir previamente o ponto de saturação e, por conseguinte, o quantitativo de observações requeridas (Thiry-Cherques, 2008; 2009).

Adotou-se a análise temática ou categorial como forma principal de técnica de análise de conteúdo. Conforme Bardin (2011), este tipo de análise consiste no desmembramento do texto em unidades e categorias, objetivando descobrir os núcleos de sentidos que compõem a comunicação. As categorias estabelecidas para análises foram as seguintes: i) Predomínio de divergência (desconfiança e resistências); ii) Predomínio de convergência (aceitação e integração); iii) Alternância de cenários (relativismo e contexto de autonomia).

Foram desenvolvidos relatórios de entrevistas a partir dos dados coletados na pesquisa de campo. Os procedimentos de análises foram executados por meio de tabulações no programa Microsoft Exce ${ }^{\circledR} 2010$, sendo a análise descritiva utilizada para processamento deles. Os dados foram segmentados por questões do roteiro de entrevista e conforme as categorias prévias e as categorias estabelecidas a posteriori.

\section{O OLHAR DESPROPORCIONAL DO CNJ}

A presença do CNJ no cenário do Sistema Ju- dicial brasileiro não foi vista por bons olhos desde o início, ou melhor, desde os momentos prévios de discussões sobre a Reforma do Judiciário. O desconhecimento do funcionamento desta nova instituição e a percepção de atuar como órgão de controle fazia com que a sua criação não fosse bem vista pela maioria da magistratura. O contexto histórico dos momentos que antecederam a criação do CNJ foi objeto de atenção dos ex-conseIheiros que estiveram mais presentes durante os debates e discussões sobre o projeto de Reforma do Judiciário.

Um dos aspectos discutidos consistia nos critérios e definições das representações que ocupariam o cargo de conselheiro do $\mathrm{CNJ}$. O entrevistado MAG 06 relembrava da insatisfação que se tinha há época em que os representantes da Justiça Estadual estavam em menor número do que a proporção representativa deste segmento em termos de quantidade de processos em tramitação, do valor das despesas, do quantitativo de magistrados e de servidores. Os dados do relatório Justiça em Números (DPJ, 2014) referentes ao ano de 2013 demonstra claramente esta distorção, pois a Justiça Estadual concentra aproximadamente 55\% das despesas do Judiciário, 69\% dos magistrados e $65 \%$ dos servidores, sendo $78 \%$ dos processos que tramitaram nesta Justiça conforme pode ser visto na Figura 2.

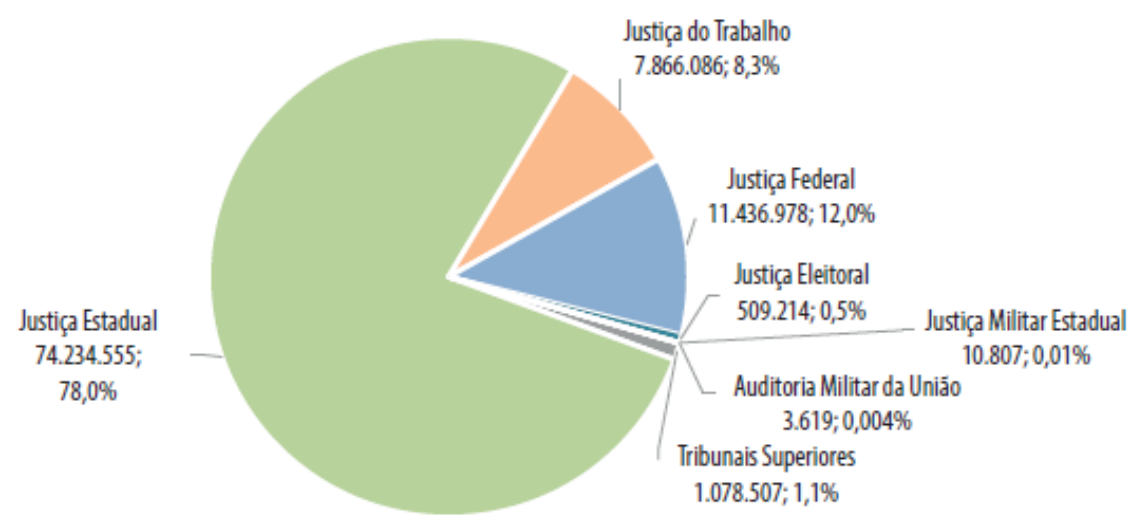

Figura 2: Total de processos em tramitação por segmento de Justiça. Fonte: DPJ (2014, p. 33). 
Os dados mais recentes do Relatório Justiça em Números (DPJ, 2018), reforçam a ideia de capilaridade das unidades judiciais exercida pela Justiça Estadual frente aos outros segmentos de Justiça. Na Figura 3, pode-se perceber o predomínio das 10.035 varas e juizados especiais da
Justiça Estadual que estão inseridas em 2.697 comarcas e representam mais da metade da estrutura de atendimento do Poder Judiciário nacional. Em termos de representatividade, essas unidades judiciais estão presentes em cerca de $48,4 \%$ dos municípios brasileiros.

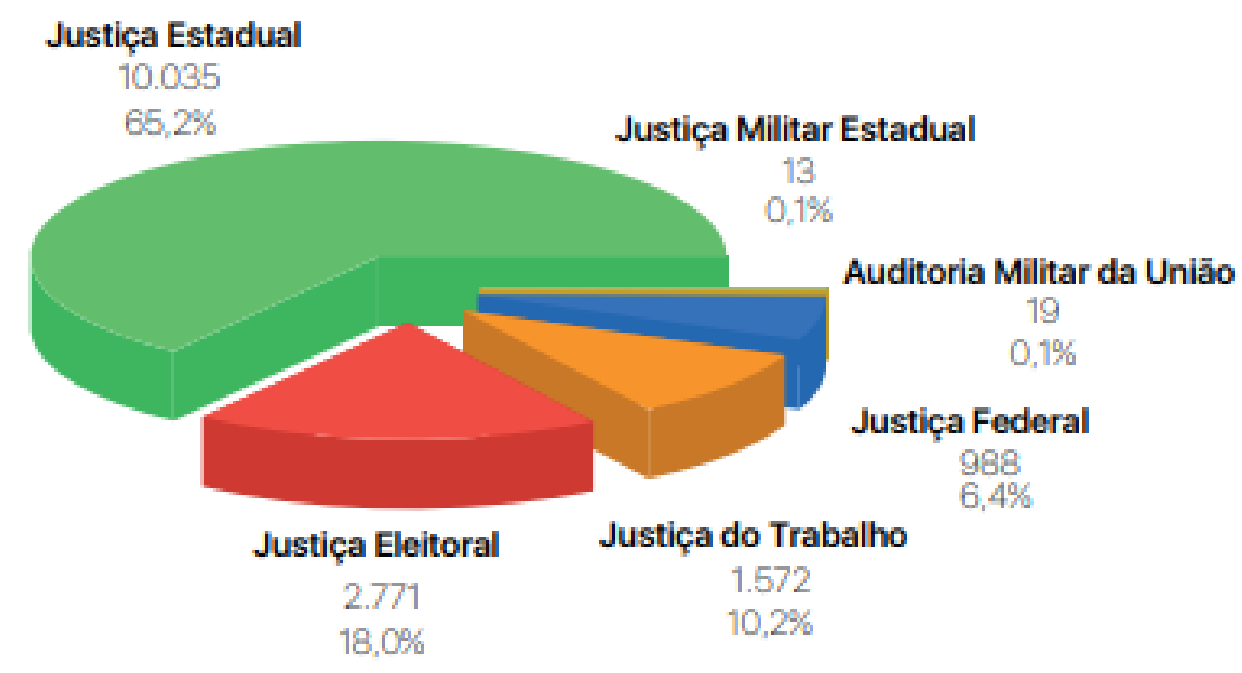

Figura 3: Unidades judiciárias de $1^{\circ}$ grau, por ramo da justiça, em 2017.

Fonte: DPJ (2018, p. 18).

Os relatórios diferentes apenas reforçam a visão do MAG 06 de que a desproporção do segmento da Justiça Estadual é um dos principais motivos de incompreensão do CNJ para as demandas deste segmento. Este argumento foi levado em consideração por outros representantes do segmento (MAG03; MAG05; MAG08), mas que não estiveram presentes nas discussões que anteviram a criação do CNJ. Desta forma, pode-se perceber o quanto os magistrados que atuam neste segmento são capazes de entender o significado das atividades de caráter nacional promovidas pelo $\mathrm{CNJ}$, mas não se atentam para as diferenças dos TJs dado que atuam num contexto estadual. Os magistrados MAG 03, MAG 05 e MAG 08 enfatizaram a existência de uma federalização das ações do CNJ que impactam no contexto local e não são bem compreendidas com a realidade dos Estados.

Outro ponto de divergência consiste nos dois conselheiros que seriam escolhidos pelo Poder Legislativo para representar a sociedade. O entrevistado LEGO2 lembra que o grande entrave era a preocupação dos magistrados em ter um ocupante de mandato legislativo (deputado federal ou senador) dentro do CNJ. Os magistrados tinham receio deste controle e argumentavam na independência e harmonia entre 
os Poderes que são pregados pela Constituição Federal. Segundo o MAG 07, havia uma pressão, principalmente por parte da Câmara dos Deputados, de colocar parlamentares dentro do CNJ para ampliar o foco disciplinar contra o Judiciário. Havia pouca resistência neste sentido no Senado, quando comparado com a radicalização proposta pelas lideranças dos partidos na Câmara dos Deputados. O entrevistado MAG07 enfatizou intensamente esse receio por parte dos magistrados e como forma de evitar esta intromissão, argumentava que caso fosse aprovada à legislação com a possibilidade de um mandatário do Legislativo como conselheiro, certamente seria considerada inconstitucional pelo STF. Neste caso, havia o risco de o CNJ ganhar um discurso político voltado exclusivamente para a repressão à magistrados e aos tribunais. A solução encontrada, segundo LEGO2, foi garantir a presença de cidadãos indicados por cada uma das casas legislativas e que tivessem a reputação ilibada e o notável saber jurídico. Desta forma, seria mais fácil garantir uma aprovação por parte da magistratura, embora ainda não fosse bem-vinda a criação do CNJ. Destaca-se também que essas indicações por parte do Legislativo são objetos de questionamentos frequentes, principalmente, com relação aos critérios de indicação destes cidadãos (Fragale Filho, 2011; 2013; Falcão; Rangel, 2013).

São recorrentes os comentários sobre a importância do presidente do STF na época, ex-ministro Nelson Jobim, na articulação política para a efetivação da Reforma do Judiciário. Os entrevistados LEGO2, OABO3, MAG05, MAG13 reconheceram como essencial o papel do ex-ministro para garantir a criação do CNJ e trabalhar com a estruturação inicial do órgão. Tendem a apontar a experiência e habilidade política do ex-ministro como o grande diferencial desta conquista, pois conseguia ter um bom diálogo com os representantes dos três Poderes, da OAB, do Ministério Público e das entidades classistas. Deste modo, as resistências para aprovação da Reforma do Judiciário diminuíram, mesmo assim muitas resistências precisavam ser enfrentadas após o estabelecimento do CNJ como órgão responsável pelo controle administrativo e financeiro dos tribunais e de fiscalizatório da conduta dos magistrados.

\section{A RELAÇÃO ENTRE O CNJ E OS TRIBUNAIS DE JUSTIÇA ESTADUAIS}

O desconhecimento da forma de atuação que o CNJ poderia produzir foi o principal responsável pelas resistências iniciais que os tribunais e a magistratura tinham sobre o órgão. A ideia de controle representava uma nova realidade para os magistrados e os tribunais, principalmente os vinculados ao segmento da Justiça Estadual, pois não existiam Conselhos Nacionais que promovessem a fiscalização de seus atos. O MAG 07 destacava que as primeiras resistências já vinham dentro da composição do $\mathrm{CNJ}$, devido à indicação de alguns membros que tinham um posicionamento contrário à existência de um órgão controlador para o Judiciário. Porém, estava ciente que o CNJ podia atuar dentro de dois vieses no momento de criação do órgão: um voltado para a eficiência e outro voltado para a investigação de irregularidades. Deste modo, procurou atuar como conselheiro que enfatizava a eficiência para garantir a afirmação e a estruturação de um órgão recente. O MAG07 procurou estabelecer uma agenda de trabalho do CNJ em marcos políticos que recebiam um amplo apoio da magistratura como, por exemplo, o caso do combate ao 
nepotismo. Apesar do CNJ ter sido alvo de ações judiciais no STF promovidas pela Associação de Magistrados Brasileiros (AMB), havia uma aceitação por parte da magistratura pelo fim do nepotismo no Judiciário conforme apontado por Sadek (2006) num levantamento realizado com os associados da própria AMB.

A maioria dos entrevistados reforça que os primeiros momentos da relação entre o CNJ e os tribunais foram marcados pelo nível elevado de divergências. Além dos posicionamentos contrários obtidos internamente (conforme mencionado pelo MAG07) e judicialmente (pelas ações da AMB), havia também as resistências geradas principalmente pelos tribunais de grande porte do segmento da Justiça Estadual (representados principalmente pelo TJSP e pelo TJRJ). Segundo LEG02 e MAG12, havia uma insatisfação da cúpula destes tribunais, pelo fato de o CNJ ser um órgão novo que já proferia ordens de mudança de gestão ou solicitava esclarecimentos para um tribunal tradicional, grande ou renomado perante as instituições jurídicas brasileiras. O MPEO1 enfatizou que o fato de os conselheiros terem status de Ministro de Estado servia como uma demonstração para os tribunais de que o CNJ estava acima deles e que deveriam prestar os esclarecimentos necessários e acatar as resoluções e recomendações estabelecidas. Por outro lado, o MAG02 e o MAG09 destacam que o CNJ enfrentava resistência de todos os Tribunais de Justiça estaduais, pois o órgão surgiu para acabar com a ausência de controle existente neste segmento. Passava uma ideia de que o CNJ teria sido criado principalmente para controlar a Justiça Estadual. Este argumento já contesta o posicionamento de Falcão, Cerdeira e ArgueIhes (2011) e Falcão et al. (2013) que sugerem a Reforma do Judiciário atendeu principalmente ao STF e de que há a necessidade de uma nova reforma. Porém, o presente trabalho visualiza o CNJ como um órgão que procura promover uma integração nacional. Então se acredita que as resistências surgiram como um movimento contra as tentativas de uniformização e padronização provenientes da ideia de Judiciário nacional e que foram apontadas por MAG07 e MAG11. Percebia-se uma perda de autonomia dos Tribunais de Justiça neste primeiro momento, pois as recomendações e resoluções alteravam o modo de atuação e organização de muitos tribunais. Servia como forma de moralização quando envolvia irregularidades, mas também de imposição de boas práticas que já vinham sendo adotadas por alguns tribunais como, por exemplo, a adoção de Planejamento Estratégico com horizonte temporal de pelo menos cinco anos e a instalação de órgão de controle interno (Azevedo, 2010).

As ações do CNJ voltadas para a promoção das ferramentas de gestão e com o foco na melhoria dos níveis de eficiência fizeram com que os tribunais de pequeno e médio porte compreendessem e aceitassem o papel deste novo órgão, conforme apontado por LEGO2, OABO2, MPEO1, LEGO3 e MAG11. Estes tribunais passaram a se beneficiar com as orientações de gestão promovidas pelo CNJ. Portanto, percebe-se que há uma transição na aceitação do CNJ e que os tribunais passaram a convergir os esforços de mudanças. Ao realizar a Pergunta Aberta do questionário, a maioria dos respondentes indicou que havia atualmente um nível de convergência entre o $\mathrm{CNJ}$ e os tribunais.

Outros cinco respondentes apontaram que existia um processo transitório entre convergência e divergência na relação entre o CNJ 
e os tribunais. O principal argumento desta posição consiste na possibilidade de interferência do CNJ frente à autonomia de gestão dos tribunais. O MAG08 comenta que o CNJ deve ser um defensor da autonomia dos tribunais, mas apresenta-se recorrentemente com a primeira instituição que interfere indevidamente nos tribunais estaduais. Este cenário gera uma tensão constante entre convergência e divergência de esforços na relação CNJ-TJs. Por outro lado, o MAG10 argumenta que os tribunais tendem a utilizar este discurso da autonomia apenas quando a situação é conveniente para eles. Reforça o argumento de alternância de cenários de convergência e divergência de esforços, mas acredita que o CNJ apresenta uma visão maior do cenário nacional e que procura diminuir as particularidades do segmento, principalmente enfrentando as dificuldades ocasionadas pelas diferenças culturais e de recursos existente em todo o país. Desta forma, o contexto socioeconômico vivenciado por cada tribunal em seus Estados acaba tendo um papel mais relevante como dificuldade a ser enfrentada num processo de inte- gração nacional.

Enquanto os outros cinco respondentes apontaram que ainda predominam divergências na relação $\mathrm{CNJ}$ e tribunais. $\mathrm{O}$ argumento principal consiste na falta de proximidade por parte do CNJ que geram problemas de comunicação e compreensão da realidade local. Apontaram que há uma visão de integração nacional que prejudica os tribunais estaduais, pois eles possuem particularidades que não são compreendidas pelos conselheiros que em sua maioria são provenientes de tribunais federais ou advogados que atuam e defendem interesses nacionais. Neste caso, percebe que os respondentes são contrários ao processo de integração nacional proposto, pois acreditam que é mais fácil solucionar os problemas locais. A visão nacional nem sempre atende as dificuldades locais que são mais urgentes, mas acabam não se tornando prioritárias, pois há a necessidade de atender rapidamente as ordens ou orientações provenientes do CNJ. Portanto, percebe-se um conflito entre o cenário nacional e o contexto local.

A Figura 4 apresenta o resumo dos respondentes conforme as categorias do estudo.

\begin{tabular}{|c|c|c|}
\hline \multicolumn{3}{|c|}{ Resumo } \\
\hline Quant. & Categoria & Entrevistado (a)s \\
\hline 5 & $\begin{array}{c}\text { Predomínio de Divergência } \\
\text { (desconfiança e resistências) }\end{array}$ & MAG06; OABO3; LEG03; MAG09; MAG13; \\
\hline 10 & $\begin{array}{l}\text { Predomínio de Convergência } \\
\text { (aceitação e integração) }\end{array}$ & $\begin{array}{l}\text { LEG02; MAG01; MAG02; MPE01; MAG03; MAG04; } \\
\text { OAB01; OABO2; MAG07; MAG11; }\end{array}$ \\
\hline 5 & $\begin{array}{l}\text { Alternância de Cenários (relati- } \\
\text { vismo e contexto de autonomia) }\end{array}$ & LEG01; MAG05; MAG08; MAG10; MAG12; \\
\hline
\end{tabular}

Figura 4: Resumo das categorias do estudo.

Fonte: Elaborado pelo autor. 


\section{CONSIDERAÇÕES FINAIS}

A participação do CNJ é vista como relevante e fundamental para o segmento da Justiça Estadual pelos seguintes aspectos: i) o desenvolvimento das ferramentas de gestão; ii) a moralização e fiscalização dos magistrados e tribunais; iii) melhoria na prestação de serviços; iv) a articulação institucional do Judiciário com os outros Poderes ou instituições ligadas ao Sistema Judicial brasileiro.

As entrevistas forneceram uma visão ampla do papel do CNJ ao longo de uma década. De forma mais ampla, os respondentes apontaram a existência de uma convergência de esforços entre o CNJ e os Tribunais de Justiça estaduais que foi sendo fortalecida na medida em que o desconhecimento e a desconfiança sobre o CNJ foram se dissipando. O CNJ é visto positivamente ao exercer o papel de coordenador dos projetos que tratam da padronização dos serviços judiciais e de políticas públicas desenvolvidas para enfrentar problemas polêmicos do Sistema Judicial (Mutirões carcerários; reconhecimento de paternidade; combate à corrupção etc.). Percebeu-se que a relação de convergência e divergência apresenta alternâncias cíclicas, pois o entendimento altera conforme a percepção de perda de autonomia por parte dos tribunais. A autonomia dos Tribunais de Justiça Estaduais é utilizada como o principal argumento para que a relação com o CNJ seja afetada, gerando uma resistência dos procedimentos de centralização e uniformização.

As principais dificuldades foram encontradas no que se refere à falta de disponibilidade de agenda dos possíveis entrevistados, o que atrapalhou o processo. Em alguns casos percebeu-se uma resistência para a realização da entrevista. Foi observado que alguns dos ex-conselheiros não tiveram interesse de abordar ou relembrar as experiências que vivenciou enquanto esteve no $\mathrm{CNJ}$, dado a quantidade de negativas recebidas para a realização da entrevista. Informalmente, alguns dos entrevistados chegaram a comentar que provavelmente não conseguiria obter respostas de determinados ex-conseIheiros. Ao questionar o motivo, respondiam que esses ex-conselheiros não eram favoráveis ao CNJ ou estiveram como conselheiros por outros interesses que não estavam ligados à essência do trabalho do CNJ.

Sugere-se que pode haver diferenças de atuação do CNJ dentro dos segmentos da Justiça Federal, Justiça do Trabalho, Justiça Eleitoral e Justiça Militar. Sobre os dois primeiros segmentos, as diferenças podem ser resultado da atuação e influência de outros Conselhos que atuam dentro destes segmentos. Enquanto os dois últimos, o $\mathrm{CNJ}$ pode atuar de forma distinta devido ao grau de especificidades do modo de trabalho destes segmentos. Em termos operacionais, recomenda-se que sejam realizados grupos focais com os conselheiros atuais e ex-conselheiros. Desta forma, alguns resultados poderiam emergir a partir das percepções entre quem se encontra no momento atual e quem esteve no CNJ anteriormente.

\section{REFERÊNCIAS}

Azevedo, J. S. F. (2010). A implantação da gestão estratégica no Judiciário brasileiro. Monografia de Especialização em Gestão Estratégica de Organizações com ênfase no Balanced Scorecard. Universidade Católica de Brasília, Brasília, DF, Brasil.

Bardin, L. (2011). Análise de Conteúdo. São Paulo: Edições 70.

Beaud, S., \& Weber, F. (2007). Guia para pesquisa de 
campo: produzir e analisar dados etnográficos. Petropólis, RJ, Vozes.

Bouckaert, G., \& Balk, W. (1991). Public productivity measurements: diseases and cures. Public Productivity \& Management, 15 (2), 229-235.

Castro, A. S. (2011). Indicadores básicos de desempenho da justiça estadual de primeiro grau no Brasil. Texto para discussão, n. 1609. IPEA, Brasília, DF, Brasil.

Creswell, J. W. (2009). Research design: qualitative, quantitative and mixed methods approaches. London, Sage.

DPJ - Departamento de Pesquisas Judiciárias. (2014). Justiça em Números 2014 - ano base 2013. Brasília: CNJ.

DPJ - Departamento de Pesquisas Judiciárias. (2018). Justiça em Números 2018 - ano base 2017. Brasília: CNJ.

Falcão, J. (2009). O Judiciário segundo os brasileiros. In: Guerra, S. (Org.). Transformações do Estado e do direito: novos rumos para o Poder Judiciário. (Vol. 1, cap. 1, pp. 13-30). Rio de Janeiro: Editora FGV.

Falcão, J., Abramovay, P., Leal, F., \& Hartmann, I. A. (2013) II Relatório Supremo em Números: o Supremo e a Federação. Rio de Janeiro: Editora FGV.

Falcão, J., Cerdeira, P. C., \& Arguelhes, D. W. (2011). I Relatório Supremo em Números: o múltiplo supremo. Rio de Janeiro: Editora FGV.

Falcão, J. \& Rangel, T. (2013). A indicação de magistrados e cidadãos para o Conselho Nacional de Justiça. In: Costa, J. A. F.; Andrade, J. M. A.; Matsuo, A. M. H. (Orgs). Direito: Teoria e Experiência - estudos em homenagem a Eros Roberto Grau. São Paulo: Malheiros Editores. 701-715.

Fragale Filho, R. S. (2007). Poder Judiciário: os riscos de uma agenda quantitativa. In: Coutinho, J. N. M., Morais, J. L. B., \& Streck, L. L. (Orgs.). Estudos Constitucionais. Rio de Janeiro: Renovar.

Fragale Filho, R. S. (2011). O Conselho Nacional de Justiça e seus possíveis impactos institucionais. Anais do Encontro Anual da Anpocs, Caxambu, MG, 35.

Fragale Filho, R. S. (2013). Conselho Nacional de Justiça: desenho institucional, construção de agenda e processo decisório. Dados. 56 (4), 975-1007.

Freitas, V. P. (1987). Justiça eficiente. Revista Jurisprudência Brasileira, 123, 23-30.

Gangemi, P. P.; Fernandes, J. (2010). Os resultados do projeto CNJ/FGV: aplicação do BSC no Judiciário brasileiro. Cadernos FGV Projetos, 5 (12), 63-71.

Glick (1983). Courts, Politics, and Justice. New York: McGraw-Hill.

Kaplan, R. S., \& Norton, D. (2004). Mapas estratégicos: convertendo ativos intangíveis em resultados tangíveis. Rio de Janeiro: Campus.

Macieira, M. E., \& Maranhão, M. (2010). Como implementar a gestão em unidades judiciárias. Rio de Janeiro: Editora FGV.

Nogueira, J. M. M. (2010). A Gestão do Poder Judiciário: uma análise do sistema de mensuração de desempenho do Judiciário Brasileiro. Dissertação de Mestrado em Administração Pública e Governo, Fundação Getulio Vargas, São Paulo, SP.

Nogueira, J. M. M. (2011). A ausência do Poder Judiciário enquanto objeto de estudo da Administração Pública brasileira. Díke - Revista eletrônica da ESMEC, 1(1), 1-17.

Nogueira, J. M. M., Oliveira, K. M. M., Vasconcelos, A. P., \& Oliveira, L. G. L. (2012). Estudo exploratório da eficiência dos Tribunais de Justiça estaduais brasileiros usando a análise envoltória de dados (DEA). Revista de Administração Pública, 46 (5), 1317-1340.

Oliveira, L. G. L (2017). Dez anos de CNJ: reflexões o envolvimento com a melhoria da eficiência do Judiciário brasileiro. Revista do Serviço Público, 68(3), 631-656. Oliveira, L. G. L., Nogueira, J. M. M., \& Pimentel, T. A. B. (2018). A continuidade da ausência do Poder Judiciário como objeto de estudos na administração pública brasileira: um levantamento de 2009 a 2017. Revista Controle, Doutrinas e Artigos, 16(2). 75-100.

Peleja Júnior, A. V. (2011). Conselho Nacional de Justiça e a magistratura brasileira. $2^{\text {a }}$ ed. Curitiba: Juruá Editora.

Sadek, M. T. (2004). Judiciário: mudanças e reformas. Estudos Avançados, 18 (51), 19-101.

Sadek, M. T. (2006). Magistrados: uma imagem em 
movimento. Rio de Janeiro: Editora FGV.

Sadek, M. T., \& Arantes, R. B. (2010). Introdução. In. Sadek, M. T. (Org.). Reforma do Judiciário. Rio de Janeiro: Centro Eldestein de Pesquisas Sociais.

Sampaio, J. A. L. (2007). O Conselho Nacional de Justiça e a independência do Judiciário. Belo Horizonte: Del Rey.

Thiry-Cherques, H. R. (2008). Métodos estruturalistas: pesquisas em ciência de gestão. São Paulo: Atlas.

Thiry-Cherques, H. R. (2009). Saturação em pesquisa qualitativa: estimativa empírica de dimensionamento. Revista Brasileira de Pesquisa de Marketing, Opinião e Mídia, 3. 20-27.

Vieira, L. J. M., \& Costa, S. G. (2013). Liderança no Judiciário: o reconhecimento dos magistrados como líderes. Revista de Administração Pública, 47 (4), 927-948.

Vieira, L. J. M, \& Pinheiro, I. A. (2008). Contribuições do Conselho Nacional de Justiça para a Gestão do Poder Judiciário. Anais do Encontro Nacional da Anpad, Rio de Janeiro, RJ, 32.

Data de submissão: 12/04/2019

Data de aceite: 19/12/2019 